\title{
Stiffness and Rutting Assessment of Asphalt Mixtures Using Steel Slag Aggregates
}

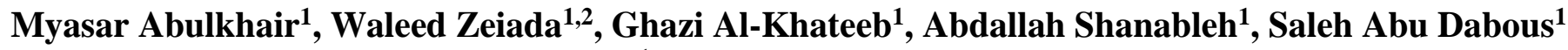 \\ ${ }^{1}$ University of Sharjah \\ Sharjah, United Arab Emirates \\ U17105556@sharjah.ac.ae; wzeiada@sharjah.ac.ae; galkhateeb@sharjah.ac.ae; shanableh@sharjah.ac.ae; \\ sabudabous@sharjah.ac.ae \\ ${ }^{2}$ Mansoura University \\ Mansoura, Egypt \\ wzeiada@mans.edu.eg
}

\begin{abstract}
Road infrastructure is one of the most important public assets. The asphalt-paved road network infrastructure represents the main means of transporting people and goods within the United Arab Emirates (UAE). Asphalt pavement surface offers many benefits including cost efficiency, reduction in noise pollution, and comfort. Stakeholders unanimously agree that enhancing the sustainability of asphalt pavements can deliver significant environmental, social, and economic benefits. Recycling of waste materials in asphalt pavements is one of the most successful sustainable practices to reduce construction cost and to save natural resources. In the UAE, steel manufacturers have been stockpiling millions of tons of steel slags that occupy large land areas which could have adverse effects on the surrounding environment. This study presents an assessment of the effectiveness of using steel slag aggregates in local hot mix asphalt (HMA) used in the wearing (surface) asphalt concrete (AC) layer. The mix designs of conventional and steel slag AC mixtures were performed to incorporate the steel slag aggregates at a 50\% replacement to the natural aggregates while maintaining the same aggregate gradation for both mixtures. The testing plan of this study included advanced characterization of the conventional and steel slag HMA mixtures. The laboratory tests conducted on the two HMA mixtures were Dynamics Modulus $\left|E^{*}\right|$ test and the Repeated Load Permanent Deformation Test (RLPDT) test, known also as Flow Number, for the assessment of stiffness and rutting respectively. The test results showed a positive impact of the steel slag aggregates on the measured laboratory performance through increasing the $\left|E^{*}\right|$ values at all test temperatures and frequencies by $37 \%$ and enhancing the rutting susceptibility of the HMA mixture through decreasing the cumulative permanent strain by $41 \%$.
\end{abstract}

Keywords: Hot Mix Asphalt - Steel Slag Aggregates - Dynamic Modulus - Rutting - Waste Materials.

\section{Introduction}

In the last few decades, there has been a growing interest in developing, evaluating and implementing more sustainable strategies and practices in pavements to preserve their environmental, social, and economics benefits. Steel slag is a byproduct of the steel manufacturing industry that can be fractionalized to produce steel slag aggregates with different sizes. Steel slag aggregates can be used as sustainable construction material in different applications such as concrete, asphalt concrete, unbounded foundation, and etc. The use of slag materials, especially thermal power plant slags and steel slags has generated better results as they can replace the natural aggregates without decreasing the roads' durability and mechanical properties [1]. Steel slag aggregates have been categorized into different types based on their production process, some of the renowned types of steel slag aggregates include; basic oxygen furnace slag (BOF), electric arc furnace slag (EAF) and secondary slags [2-4].Steel slag aggregates have been added to the HMA and evaluated for their effectiveness on the laboratory mechanical properties.

The steel slag aggregate has been proved effective in its application in asphalt pavements [5]. As aforementioned, the steel slag aggregates, when properly processed, have a higher affinity to asphalt, high angularity, and high stability that improves the rutting resistance of the mixture. Furthermore, they have high durability and better mechanical strength [6]. Due to the rough surface texture the steel slag aggregates have, the skid resistance is increased [7]. Steel slag has also been used as a mean to reduce the traffic noise of AC pavements [8]

Advanced characterization test methods were used to compare the performance of AC mixtures containing steel slag aggregates to other conventional ones. Ahmedzadea [9] investigated the effect of using steel slag aggregates on the properties 
of hot mix asphalt. The results showed that steel slag aggregates improved the mechanical and electrical conductivity of AC mixtures. Masoudi et al, [10] investigated the use of electric arc furnace steel slag coarse aggregate in warm mix asphalt subjected to long-term aging. The test results showed that the use of steel slag aggregates in warm asphalt mixture increased the Marshall Stability, stiffness, resilient modulus and indirect tensile strength. Furthermore, the warm asphalt mixtures containing steel slag showed enhanced short-term and long-term performance with less aging. Wen et al, [2] performed the dynamic modulus test to determine the stiffness values of AC mixtures over a wide range of temperatures and frequencies. It was observed that at low temperatures, use of steel slag aggregates portrayed higher dynamic modulus while at high temperatures, AC mixtures replaced by $20 \%$ steel slag showed higher dynamic modulus. In another study, a $100 \%$ replacement of limestone with steel slag aggregates led to reduction in the rutting resistance and permanent deformation under dynamic loading [11]. Ameri and Behnood [12] showed that replacement of aggregates by steel slag in AC mixture generally increased the rutting resistance of the asphalt mixture. The rutting performance of AC mixtures using lime stone aggregates and 50/50 percent of lime stone and steel slag aggregates was investigated. The results showed clear improvement of the resistance to permanent deformations at high temperatures using steel slag aggregates. Other than the HMA, the steel slag has been used in other applications in roads construction such as concrete mixtures for rigid pavements [13,14,15-22], unbound aggregates for road base [23,24], and mineral filler for AC mixture [25-27].

Currently, millions of tons of steel slag aggregates are stockpiled in the environment without any successful uses. In Abu Dhabi, more than 2 million tons of steel slag aggregate have been already stockpiled with no use from only Emirates Steel. Emirates Steel is the main steel manufacturer in the UAE and produces 800 thousand tons of steel slag aggregates annually. The recycling of these steel slag aggregates in potential applications such as the construction of local roads offers a sustainable solution to reduce the associated health problems generated from steel slag landfills. In addition, this promising sustainable practice reduces the demand on natural aggregates harvested from local mountains mainly in Al Fujairah as well as the associated manufacturing and transportation cost. With the rapid roads construction in UAE, all the local steel slag aggregates can be successfully utilized by replacing the natural aggregates in the HMA totally or at specific proportions. However, for a successful implementation of steel slag aggregates, research work is needed to consider the local climate, materials, and traffic characteristics. The main objective of this paper is to investigate the usage of local steel slag aggregates on the rutting susceptibility of AC mixtures which is a major concern in warm climate regions such as the UAE.

\section{Materials}

\section{1. Aggregates}

The Electric Arc Furnace (EAF) steel slag aggregates were obtained from Emirates Steel after the steel slag has been de-metallized, crushed, graded to the desired sizes and stockpiled. The steel slag aggregate samples were selected from three different stockpiles of coarse aggregates, fine aggregates, and mineral filler. Two AC mixtures were used in this study as follows

1. Conventional wearing (surface) AC mixture, $100 \%$ Gabbro aggregate.

2. Steel slag wearing (surface) AC mixture, 50\% Gabbro aggregate and 50\% steel slag aggregates

For the conventional wearing (surface) AC mixture, a 0-3/4" well-graded aggregates containing 100\% crushed gabbro were used. A 0-3/4" well-graded aggregates containing 50\% crushed EAF steel slag aggregates (size 5mm$19 \mathrm{~mm}$ ) and $50 \%$ crushed gabbro aggregates (size $0-5 \mathrm{~mm}$ ) were used to prepare steel slag wearing surface AC mixture. The combined blended aggregate gradations for conventional and steel slag AC mixtures are shown in Fig. 1. It is worth mentioning that the $50 \%$ steel slag proportion was selected as the maximum value that can be used without altering the design gradation of the blended aggregate. 


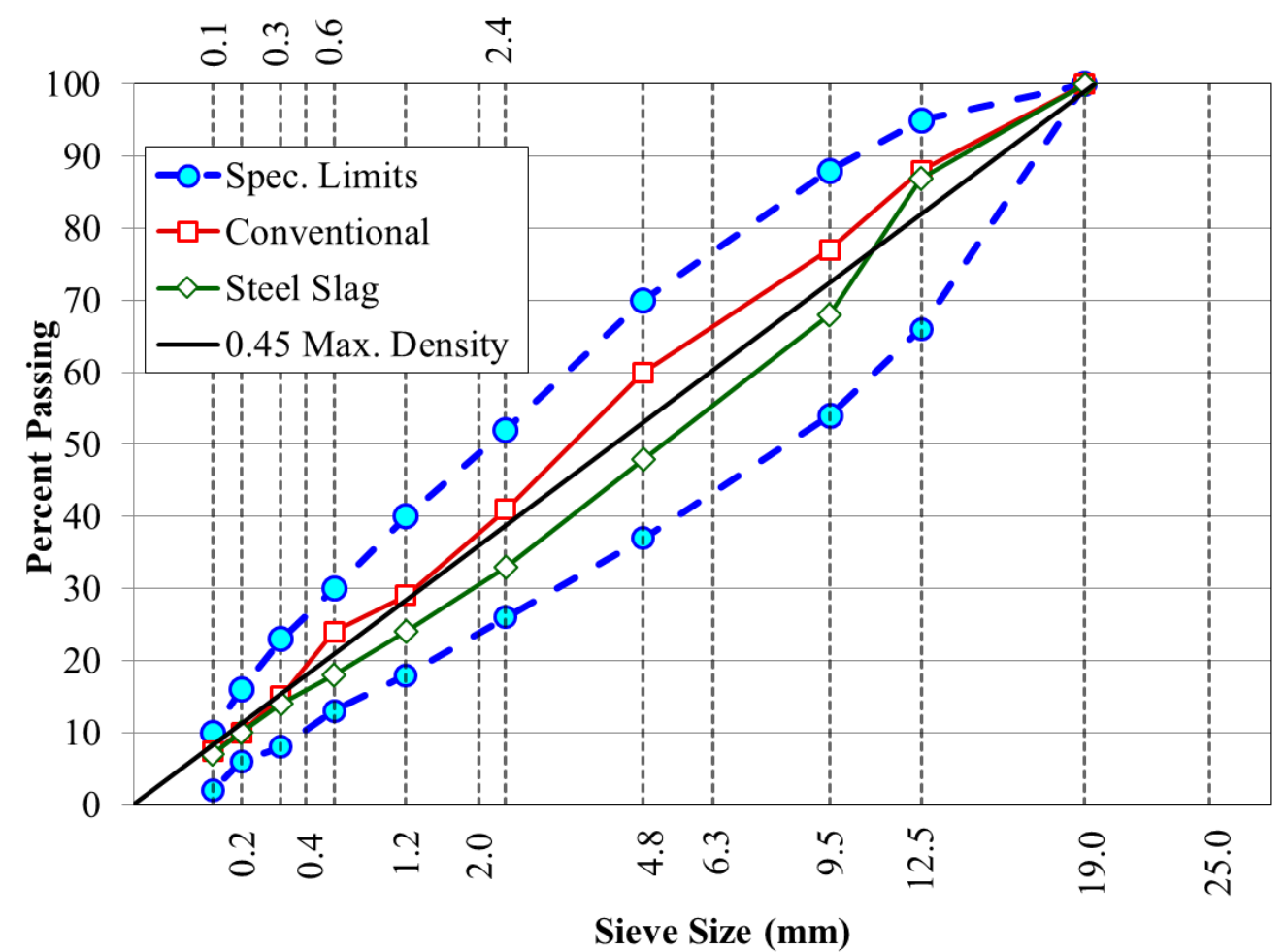

Fig. 1: Aggregate Blend Gradation of Conventional and Steel Slag Aggregates.

\section{2. Asphalt Binder}

A 40/50-penetration grade asphalt binder was used in this study. The binder grade was specified and approved by Abu Dhabi Municipality. Three tests were conducted on the asphalt binder as summarized in Table 1.

Table 1: Test Results of Asphalt Binder 40/50.

\begin{tabular}{|l|c|c|c|}
\hline \multicolumn{1}{|c|}{ Parameter } & Methods & Unit & Results \\
\hline Penetration @ $25^{\circ} \mathrm{C}(100 \mathrm{gm}) 5 \mathrm{Sec}$ & ASTM D5/ DSM - 13 & $\mathrm{dmm}$ & 44 \\
\hline Softening Point & ASTM D36/D36M-14e 1 & ${ }^{\circ} \mathrm{C}$ & 53.2 \\
\hline Rotational Viscosity at $135^{\circ} \mathrm{C}$ & ASTM D4402/D4402M - 15 & $\mathrm{cP}$ & 427 \\
\hline
\end{tabular}

\section{3. Mixes Design}

The mix design was conducted for both mixtures using Marshall mix design procedure. The volumetric properties and the Marshall test results for conventional wearing (CW) and steel slag wearing (SW) mixtures are summarized in Table 2.

Table 2: Summary of Volumetric and Mix Design Properties for both AC Mixtures.

\begin{tabular}{|c|c|c|c|c|c|}
\hline \multirow{2}{*}{ Volumetric Property } & \multicolumn{2}{|c|}{ Mixture Type } & \multicolumn{2}{c|}{ Specification } & Unit \\
\cline { 2 - 6 } & CW & SW & Minimum & Maximum & \\
\hline Design Asphalt Binder Content, $\mathrm{P}_{\mathrm{b}}$ & 3.9 & 4.1 & 3.4 & 4.2 & $\%$ \\
\hline Voids in Mix, VIM & 5.6 & 5.7 & 4 & 7 & $\%$ \\
\hline Voids in Mineral Aggregate, VMA & 14.85 & 14.95 & 14 & & $\%$ \\
\hline Voids Filled with Asphalt, VFA & 62 & 62 & 55 & 70 & $\%$ \\
\hline
\end{tabular}




\begin{tabular}{|c|c|c|c|c|c|}
\hline Mix Density at Design Asphalt Binder & 2.548 & 2.795 & & & \\
\hline Marshall Stability & 1990 & 2190 & 1500 & & $\mathrm{kgf}$ \\
\hline Flow & 2.96 & 3.16 & 2 & 4 & $\mathrm{~mm}$ \\
\hline Stiffness Quotient & 672 & 693 & 450 & & $\mathrm{Kgf} / \mathrm{mm}$ \\
\hline Effective Specific Gravity $\left(\mathrm{G}_{\mathrm{se}}\right)$ & 2.887 & 3,229 & & & \\
\hline Average Bulk Density $\left(\mathrm{G}_{\mathrm{sb}}\right)$ & 2.874 & 3.158 & & & \\
\hline $\begin{array}{c}\text { Theoretical Maximum Specific Gravity } \\
\left(\mathrm{G}_{\mathrm{mm}}\right)\end{array}$ & 2.691 & 2.975 & & & \\
\hline Specific Gravity of Bitumen & 1.034 & 1.034 & & & \\
\hline
\end{tabular}

\section{Specimen Manufacturing}

The target air voids level for the test specimens was 7\% (corresponding to initial field compaction). Three trial specimens were mixed and compacted using a Superpave gyratory compactor to determine the required sample weight that is corresponding to the target air voids. To compact the specimens, both heated aggregates and asphalt were mixed using mechanical mixer and then short-term aged for 4 hours at $135^{\circ} \mathrm{C}$. The short-term aged mixtures were then heated to the compaction temperature $\left(140^{\circ} \mathrm{C}\right)$. The asphalt mixtures were then placed in the compaction mold and compacted using the Superpave Gyratory Compactor. The samples of both AC mixtures were compacted to $180 \mathrm{~mm}$ in height and $150 \mathrm{~mm}$ in diameter. To obtain testable specimens with consistent air voids distributions, small specimens were cored and cut to 150 $\mathrm{mm}$ in height and $100 \mathrm{~mm}$ in diameter. The coring and cutting of all specimens were done using state-of-the-art auto-saw and advanced asphalt multi-core drill to assure smooth and leveled surfaces which is a key for accurate test results. The AASHTO T166-00 was then followed to measure the bulk specific gravity, air voids and water absorption of the specimens using saturated surface-dry (SSD) specimens [28]. The measured SSD air voids and the bulk specific gravity for test specimens are listed in Table 3.

Table 3: No. of Gyration, Bulk Sp. Gr., Maximum Sp. Gr., and Saturated Surface Dry Air Voids of the Flow Number (FN) Test Specimens.

\begin{tabular}{|c|c|c|c|c|c|}
\hline Mixture Type & $\begin{array}{l}\text { Specimen } \\
\text { ID }\end{array}$ & $\begin{array}{l}\text { Bulk S.G. } \\
\qquad \mathrm{G}_{\mathrm{mb}}\end{array}$ & $\begin{array}{c}\text { Measured Max. } \\
\text { S.G. } \\
\text { G }_{\mathrm{mm}}\end{array}$ & $\begin{array}{c}\text { SSD Air Voids } \\
(\%)\end{array}$ & $\begin{array}{c}\% \\
\text { Absorption }\end{array}$ \\
\hline \multirow{8}{*}{$\begin{array}{c}\text { Conventional } \\
\text { Wearing }\end{array}$} & \multicolumn{5}{|c|}{ Dynamic Modulus, $|E *|$ Test Specimens } \\
\hline & $\mathrm{CW}-2$ & 2.498 & \multirow{3}{*}{2.691} & 7.4 & 0.7 \\
\hline & $\mathrm{CW}-3$ & 2.498 & & 7.4 & 0.9 \\
\hline & $\mathrm{CW}-6$ & 2.486 & & 7.5 & 1.1 \\
\hline & \multicolumn{5}{|c|}{ Flow Number Test Specimens } \\
\hline & $\mathrm{CW}-7$ & 2.488 & \multirow{3}{*}{2.691} & 7.5 & 0.9 \\
\hline & $\mathrm{CW}-8$ & 2.494 & & 7.3 & 1.0 \\
\hline & $\mathrm{CW}-9$ & 2.484 & & 7.5 & 0.8 \\
\hline \multirow{8}{*}{$\begin{array}{l}\text { Steel Slag } \\
\text { Wearing }\end{array}$} & & Dynam & Modulus, $\left|E^{*}\right| \mathrm{Te}$ & Specimens & \\
\hline & SW -1 & 2.767 & \multirow{3}{*}{2.975} & 7.0 & 0.3 \\
\hline & SW -2 & 2.753 & & 7.4 & 0.3 \\
\hline & SW -3 & 2.759 & & 7.3 & 0.2 \\
\hline & \multicolumn{5}{|c|}{ Flow Number Test Specimens } \\
\hline & SW -4 & 2.767 & \multirow{3}{*}{2.975} & 7.2 & 0.4 \\
\hline & $\mathrm{SW}-5$ & 2.767 & & 6.9 & 0.3 \\
\hline & SW -6 & 2.774 & & 6.7 & 0.2 \\
\hline
\end{tabular}




\section{Test Methods}

\section{1. Dynamic Modulus $\left|E^{\star}\right|$ Test}

The viscoelastic response of asphalt concrete mixtures can be captured through mechanical tests conducted in the linear viscoelastic range. Viscoelastic behavior of asphalt concrete mixtures can be described by different mechanical properties. These mechanical properties are complex modulus, relaxation modulus, and creep compliance. For linear viscoelastic materials such as asphalt mixes, the stress-strain relationship under a continuous sinusoidal loading is defined by a complex number called the complex modulus $E^{*}[29,30]$. In the Mechanistic-Empirical Pavement Design Guide (MEPDG), according to the current protocol, complex modulus testing of asphalt materials is conducted using axial haversine loading waveform (AASHTO T 342-11) [31]. Three specimens for each mix, $100 \mathrm{~mm}$ in diameter and $150 \mathrm{~mm}$ in height, were tested using a Universal Testing Machine (UTM $30 \mathrm{KN}$ ) at $-10,4.4,21,37.8$ and $54.4^{\circ} \mathrm{C}$ and $25,10,5,1,0.5$, and $0.1 \mathrm{~Hz}$ loading frequencies. The stress levels at individual temperature and frequency conditions were chosen to keep the measured recoverable axial strain within the viscoelastic range (up to $150 \mu \varepsilon$ ). The axial deformations of the specimens are measured using three spring-loaded Linear Variable Differential Transducers (LVDTs) placed vertically at $120^{\circ}$ around the specimen side.

\section{2. Construction of $\left|E^{\star}\right|$ Master Curve}

The master curves were constructed for both mixtures using the $\left|E^{*}\right|$ values, according to the well reported method of numerical optimization [29]. The master curve is mathematically modeled using the sigmoidal function as shown in Equation (1):

$$
\log \left|E^{*}\right|=\delta+\frac{\alpha}{1+\frac{1}{e^{\beta+\gamma\left(\log f_{r}\right)}}}
$$

where:

$f_{\mathrm{r}} \quad=$ reduced frequency of loading,

$\delta \quad=$ minimum value of $\left|E^{*}\right|$

$\delta+\alpha=$ maximum value of $\left|E^{*}\right|$

$\beta, \gamma=$ parameters describing the shape of the sigmoidal function

The reduced frequency is the product of the test frequency and the time-temperature shift factor, $a_{T}$, which is a temperature, $T$, dependent value that quantifies the amount of horizontal shift necessary to create a continuous master curve. In this study, the second-degree polynomial function with coefficients $a, b$ and $c$, Equation 2, is adopted.

$$
\log a_{T}=a T^{2}+b T+c
$$

\section{3. Repeated Load Permanent Deformation (TRLPD) or Flow Number Test}

The TRLPD test, known as a flow number test (FN), is used to determine the permanent deformation characteristics of paving materials. A sample is subjected to an all-around confining pressure at a high temperature to simulate the critical condition when rutting may occur. A repeated haversine load pulse is applied for a period of 0.1 second on the sample then rests for 0.9 seconds during which time the recovered strains are monitored. Two parameters are of interest: 1) the slope of the secondary region is used in predicting pavement rutting and 2) the cycle where the tertiary cycle begins is useful to rank and select AC mixtures. The number of loading cycles at which tertiary flow occurs, is referred to as the Flow Number $(F N)$. The Francken model developed in 1977 was found to be the most comprehensive representation of the permanent deformation test data [32]. The mathematical model for the regression analysis is shown in Equation (3).

$$
\varepsilon_{p}(N)=A(N)^{B}+C\left(e^{D(N)}-1\right)
$$


where, $\varepsilon_{p}(N)$ is the permanent deformation or permanent strain, $N$ is the number of loading cycles, and A, B, C and $\mathrm{D}$ are Regression constants. nonlinear regression techniques are used to determine the model's coefficients. The strain rate of change is estimated using first derivative of Equation (3).

Two AC mixtures were tested to determine the $F N$. Three different cylindrical replicates of $100 \mathrm{~mm}$ in diameter and $150 \mathrm{~mm}$ in height were prepared targeting air voids of $7 \pm 0.5 \%$ and according to the AASHTO TP 79-13 protocol. All repeated load unconfined $F N$ tests were carried out at $54.4{ }^{\circ} \mathrm{C}$ and at the same deviatoric axial stress $\left(\sigma_{\mathrm{d}}\right)$ for direct comparison purposes.

\section{Results and Discussion}

\section{1. 1. Dynamic Modulus, $\left|E^{\star}\right|$ Test Results}

This section provides a comparison of the $\left|E^{*}\right|$ values of conventional and steel slag AC mixtures (Fig. 2 (a)). It can be observed from Fig. 2 that the steel slag AC mixture exhibited higher $\left|E^{*}\right|$ values compared to the conventional AC mixture. Although the $\left|E^{*}\right|$ master curves can be used for general comparison between the conventional and steel slag AC mixtures, but specific temperature-frequency combination values need to be evaluated separately. It is worth mentioning that the $\left|E^{*}\right|$ values obtained from the three replicates were very consistent and showed an average coefficient of variation of $9.5 \%$ and $5.1 \%$ for the conventional and steel slag AC mixtures respectively. The maximum allowed coefficient of variation as per the AASHTO T 342-11 protocol using three replicates and 3 LVDTs mounted on each replicate is $12.0 \%$.
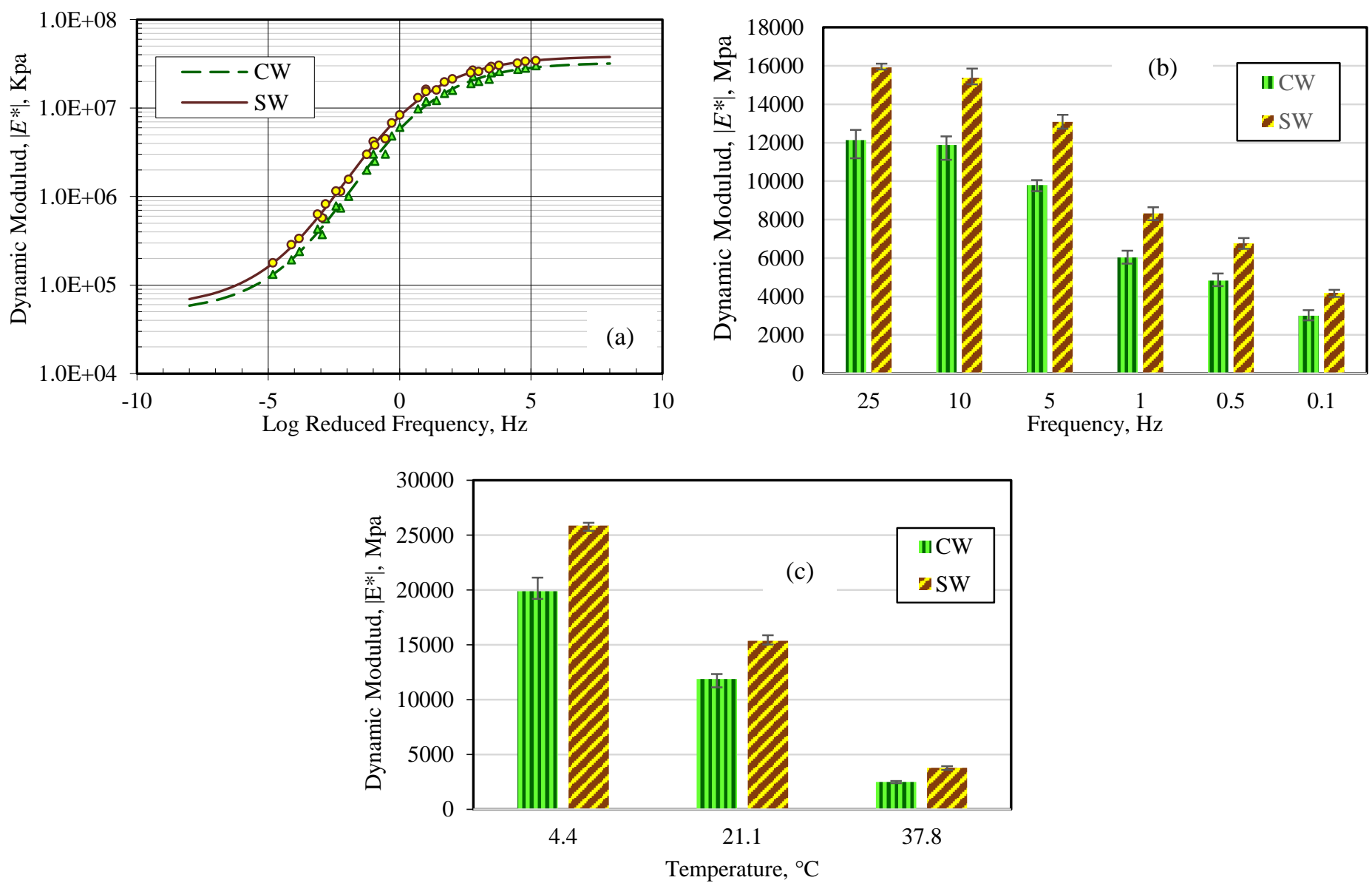

Fig. 2: (a) Comparison of $\left|E^{*}\right|$ Master Curves; (b) Comparison of $\left|E^{*}\right|$ Values at $21.1^{\circ} \mathrm{C}$; and (c) Comparison of $\left|E^{*}\right|$ Values at $10 \mathrm{~Hz}$ Frequency. 
Fig. 2 (b) show comparisons of $\left|E^{*}\right|$ values of the wearing (surface) AC mixtures with and without steel slag aggregates. Although this comparison is only for $21.1^{\circ} \mathrm{C}$ at all frequencies, the same trend was found for other test temperatures. It can be observed that the $\mathrm{AC}$ mixture with steel slag aggregates revealed higher $\left|E^{*}\right|$ values compared to the conventional $\mathrm{AC}$ mixture. Another comparison is made at multiple test temperatures of $4.4,21.1$ and $37.8^{\circ} \mathrm{C}$ and one loading frequency of $10 \mathrm{~Hz}$ as shown in Fig. 2 (c). The $21.1^{\circ} \mathrm{C}$ and $10 \mathrm{~Hz}$ represents similar test conditions for the resilient modulus test required for the AASHTO 1993 pavement structural design. The analysis showed that the $\left|E^{*}\right|$ of wearing (surface) AC mixture was $30 \%$ higher than the conventional wearing surface $\mathrm{AC}$ mixture. Considering $\left|E^{*}\right|$ results at all temperatures and frequencies, it was found that using steel slag aggregates increased the $\left|E^{*}\right|$ on average by $37 \%$.

\section{1. 2. Repeated Load Permanent Deformation (TRLPD) or Flow Number Test}

The cumulative permanent strain as a function of the number of loading cycles for the three replicates for each AC mixture is shown in Fig. 3. It can be observed clearly that all the tested replicates experienced a tertiary flow where the cumulative permeant strain started to increase rabidly after the secondary stage indicating a shear failure. This is typically useful in calculating the flow number of tested specimens. Moreover, it is clear that the conventional AC replicates exhibited higher cumulative permanent strain compared to the steel slag AC replicates. This means the steel slag provides better aggregate interlock that helps in resisting permanent deformation.

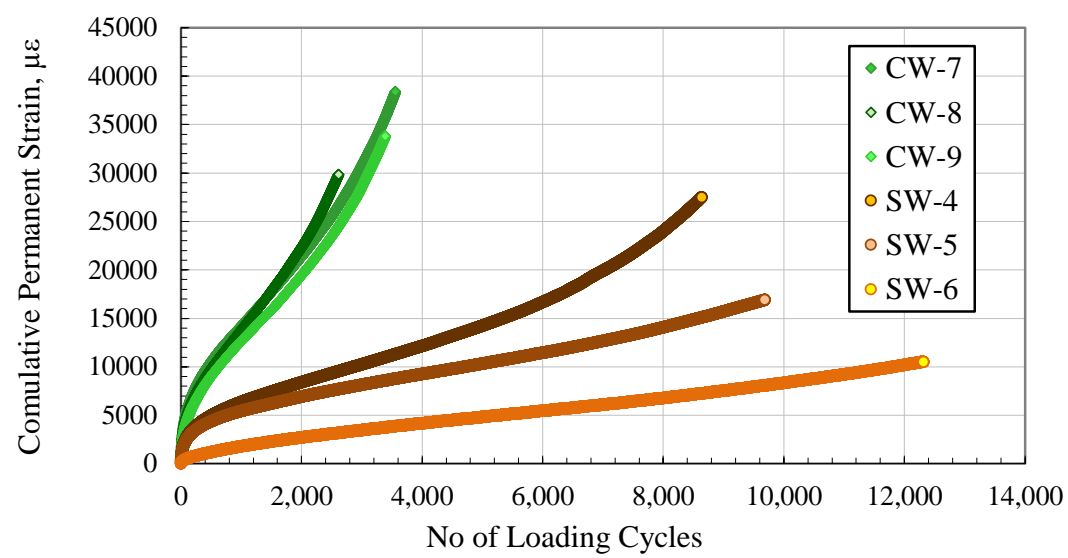

Fig. 3: Repeated Load / Flow Number Results for Conventional Wearing Surface and Steel Slag Wearing Surface AC Mixtures.

Non-linear regression analysis was conducted using Statistica Software to fit the cumulative permanent deformation relationships in order to calculate the Flow Number $(F N)$ and both corresponding permanent strain $\left(\varepsilon_{P}\right)$ and resilient strain $\left(\varepsilon_{R}\right)$ values that are quite useful in pavement design applications. The model regression coefficients as well as the $F N, \varepsilon_{P}$, and $\varepsilon_{P} / \varepsilon_{R}$ results are summarized in Table 4 . The presented results showed that the steel slag aggregates demonstrated preferable characteristics in mitigating permanent deformation and rutting including higher FN, and lower corresponding $\varepsilon_{P}$, and $\varepsilon_{P} / \varepsilon_{R}$.

Table 4: Master Summary of Flow Number Test Results for All Tested AC Mixtures.

\begin{tabular}{|c|c|c|c|c|c|c|c|c|c|c|}
\hline \multirow{2}{*}{ Mix Type } & \multirow{2}{*}{$\begin{array}{l}\text { Specimen } \\
\text { ID }\end{array}$} & \multicolumn{4}{|c|}{ Regression Coefficients } & \multirow{2}{*}{$\mathrm{R}^{2}$} & \multirow{2}{*}{$\begin{array}{c}\text { Flow } \\
\text { Number } \\
\text { (cycles) }\end{array}$} & \multirow{2}{*}{$\begin{array}{c}\text { Permanent } \\
\text { Deformation, } \\
\varepsilon_{P}(\mu \varepsilon) \\
\end{array}$} & \multirow{2}{*}{$\begin{array}{c}\text { Resilient } \\
\text { Deformation, } \\
\varepsilon_{R}(\mu \varepsilon) \\
\end{array}$} & \multirow{2}{*}{$\begin{array}{c}\varepsilon_{P} / \varepsilon_{R} \\
\text { (Ratio) }\end{array}$} \\
\hline & & A & $\mathrm{B}$ & $\mathrm{C}$ & $\mathrm{D}$ & & & & & \\
\hline \multirow{3}{*}{$\begin{array}{l}\text { Conventional } \\
\text { Wearing }\end{array}$} & $\mathrm{CW}-7$ & 1007.5 & 0.3658 & 1716.8 & 0.00069 & 0.999 & 1272 & 16144 & 438 & 36.86 \\
\hline & CW -8 & 811.42 & 0.3865 & 1667.7 & 0.00083 & 0.999 & 1024 & 14023 & 422 & 33.23 \\
\hline & $\mathrm{CW}-9$ & 644.775 & 0.41494 & 1134.3 & 0.00078 & 0.999 & 1269 & 14419 & 409 & 35.25 \\
\hline & SW -4 & 639.721 & 0.3209 & 1510.2 & 0.00027 & 0.999 & 2734 & 9766 & 361 & 27.05 \\
\hline
\end{tabular}




\begin{tabular}{|l|c|c|c|c|c|c|c|c|c|c|}
\cline { 2 - 11 } \multirow{2}{*}{$\begin{array}{l}\text { Steel Slag } \\
\text { Wearing }\end{array}$} & SW - 5 & 626.707 & 0.306 & 1049.7 & 0.0002 & 0.999 & 4158 & 9421 & 352 & 26.76 \\
\cline { 2 - 11 } & SW - 6 & 10.51 & 0.722 & $6.9 \mathrm{E}-05$ & 0.00138 & 0.998 & 8657 & 7269 & 359 & 20.25 \\
\hline
\end{tabular}

Figure 3 (a) shows a comparison of the average $F N$ between the two AC mixtures. It is noticed that the Steel slag mixture have $F N$ values that are 4.4 times higher than those of the conventional mixture. Fig. 4 (b) shows a comparison of the average permanent strain values for the two AC mixtures. The steel slag AC mixture exhibited $41 \%$ lower permanent deformation than the conventional AC mixture at failure. Fig. 4 (c) reveals that the steels slag AC mixture has $15.6 \%$ lower resilient strain at failure compared to the conventional AC mixture.
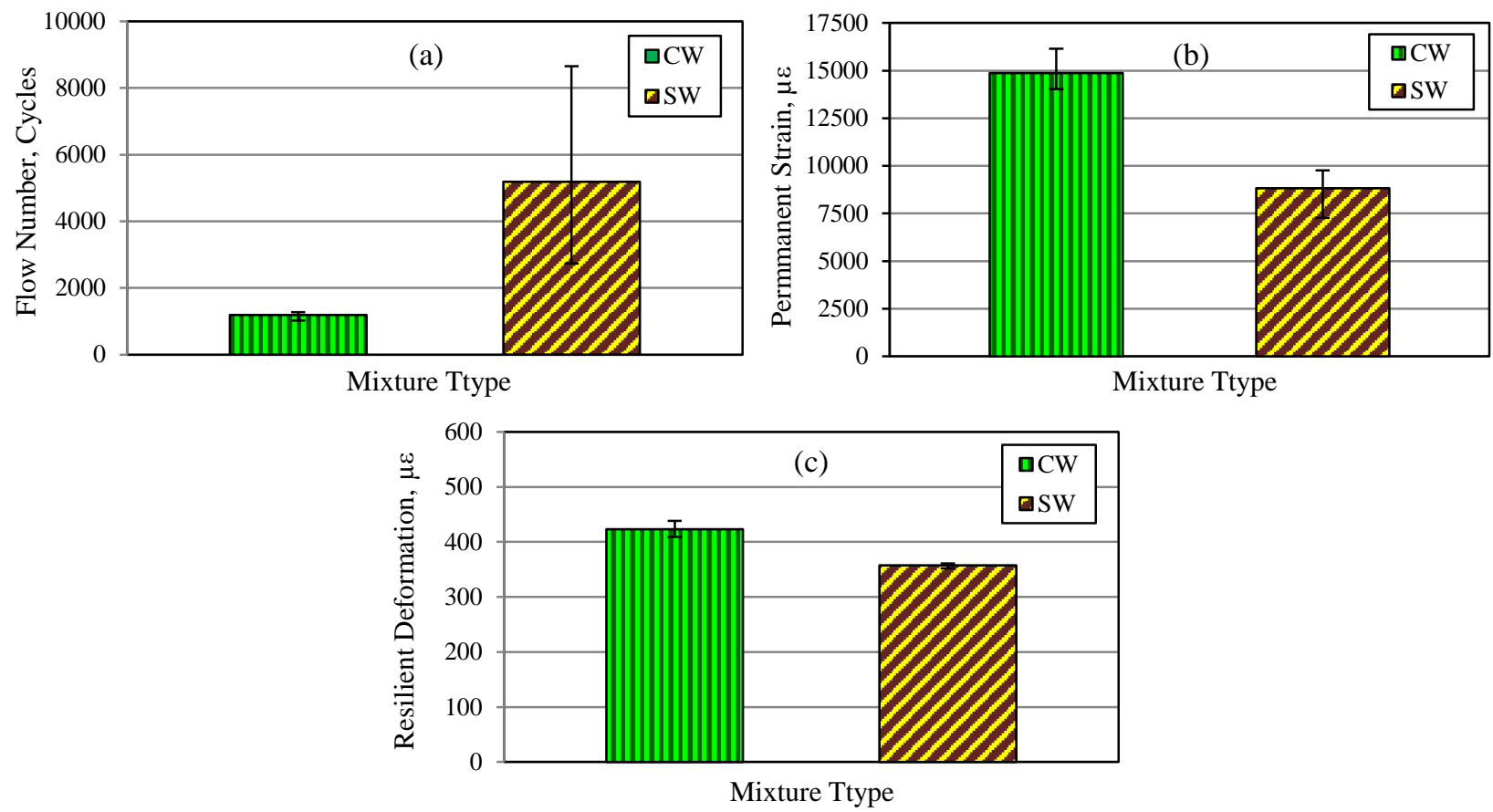

Fig. 4: (a) Comparison of Average Flow Number; (b) Comparison of Average Permanent Deformation; (c) Comparison of Average Resilient Deformation.

\section{Summary and Conclusion}

In this study, laboratory experimental program was conducted to determine the mechanical properties of AC mixtures with and without steel slag aggregates, including dynamic modulus and repeated load for permanent deformation characterization. Conventional wearing (surface) AC mixture using traditional gabbro aggregates was considered as control AC mixture. A steel slag AC mixture with 50\% steel slag aggregates replacement using the same gradation was designed for comparison purposes. All tests were carried out on cylindrical specimens with $100 \mathrm{~mm}$ in diameter and $150 \mathrm{~mm}$ in height. For each AC mixture, three replicates were prepared for each test. The following conclusions were attained from this study:

- The $\left|E^{*}\right|$ master curves of both AC mixtures showed that the steel slag AC mixture exhibited higher $\left|E^{*}\right|$ values compared to the conventional AC mixture.

- The use of steel slag aggregates in asphalt mixtures was found to increase the $\left|E^{*}\right|$ value over a wide range of temperatures and loading frequencies by $37 \%$ compared to the conventional AC mixture.

- Considering test conditions for the AASHTO 1993 pavement structural design $\left(21.1^{\circ} \mathrm{C}\right.$ and $\left.10 \mathrm{~Hz}\right)$, the $\left|E^{*}\right|$ of steel slag AC mixture was 30\% higher than the conventional AC mixture. This indicates that utilization of steel 
slag aggregates in asphalt mixtures is expected to increase the AC layer coefficient and therefore reduces the layer thickness while maintaining the same performance.

- The TRLPD test results demonstrated that the steel slag AC mixture exhibited higher $F N$ values than the conventional AC mixture.

- The steel slag AC mixture displayed 41\% lower permanent strain compared to the conventional AC mixture. This indicates that the steel slag mixture has the potential to resist rutting better than the conventional AC mixture.

- Ongoing research effort is undertaken to assess the impact of steel slag aggregate on fatigue cracking and moisture damage considering additional aggregates gradation.

\section{Acknowledgements}

The paper was prepared as a part of a research project titled "Evaluation of Asphalt Mixtures with Steel Slag Aggregates Using Advanced Characterization Tests: Pilot Study at Musaffah Intersection, Abu-Dhabi". The authors would like to thank the Tube City IMS and Emirates Steel for funding this study. The authors offer their gratitude to Eng. Khalil Al-Mbaidheen, Eng, Mohamed Al-Ani, Eng. Kusi Al-Naser, Eng. Sarah Ayman, Eng. Ayat Gamal, Eng. Helal Ezzat, Dr. Hanqi Liu for their help and guidance in this study.

\section{References}

[1] Sun, Daquan, et al., "A comprehensive review on self-healing of asphalt materials: Mechanism, model, characterization and enhancement," Advances in colloid and interface science., vol. 256, pp. 65-93, 2018

[2] Wen, Haifang, Edward Wu, and Sushanta Bhusal, "Evaluation of steel slag as hot mix asphalt aggregate," Final report, Edw. C. Levy Co. and Nucor Steel Seattle, Seattle, WA, 2014.

[3] Skaf, M., et al, "Ladle furnace slag in asphalt mixes," Construction and Building Materials., vol. 122, pp. 488-495, 2016.

[4] Yiying, H. O. N. G., et al, "Steel Slag Aggregate for Asphalt Pavement," 2015.

[5] Geiseler, J., "Use of steelworks slag in Europe," Waste management., vol. 16.1-3, pp. 59-63, 1996.

[6] Chica, José A., et al, "KUBIK: Open building approach for the construction of an unique experimental facility aimed to improve energy efficiency in buildings," Open House International,. vol. 36, no.1, pp. 63, 2011.

[7] Florida Department of Transportation, Annual report, 2011.

[8] Noureldin, A. Samy, and Rebecca S. McDaniel, "Evaluation of surface mixtures of steel slag and asphalt." Transportation Research Record., vol. 1269, 1990.

[9] Ahmedzade, Perviz, and Burak Sengoz, "Evaluation of steel slag coarse aggregate in hot mix asphalt concrete," Journal of hazardous materials, vol. 165, no.1-3, pp. 300-305, 2009.

[10] Masoudi, Sajjad, Sayyed Mahdi Abtahi, and Ahmad Goli, "Evaluation of electric arc furnace steel slag coarse aggregate in warm mix asphalt subjected to long-term aging," Construction and Building Materials,. vol. 135, pp. 260-266, 2017.

[11] Asi, Ibrahim M., Hisham Y. Qasrawi, and Faisal I. Shalabi, "Use of steel slag aggregate in asphalt concrete mixes," Canadian Journal of Civil Engineering, vol. 34, no. 8, pp. 902-911, 2007.

[12] Ameri, Mahmoud, and Ali Behnood, "Laboratory studies to investigate the properties of CIR mixes containing steel slag as a substitute for virgin aggregates," Construction and Building Materials, vol. 26, no. 1, pp. 475-480, 2012.

[13] Manso, Juan M., Javier J. Gonzalez, and Juan A. Polanco, "Electric arc furnace slag in concrete," Journal of materials in civil engineering, vol. 16, no. 6, pp. 639-645, 2004.

[14] Pellegrino, Carlo, and Vittorio Gaddo, "Mechanical and durability characteristics of concrete containing EAF slag as aggregate," Cement and Concrete Composites, vol. 31, no. 9, pp. 663-671, 2009.

[15] Etxeberria, M., et al, "Properties of concrete using metallurgical industrial by-products as aggregates," Construction and Building Materials, vol. 24, no. 9, pp. 1594-1600, 2010.

[16] Montgomery, D. G., and Guangmin Wang, "Instant-chilled steel slag aggregate in concrete-strength related properties," Cement and concrete research, vol.21, no. 6, pp. 1083-1091, 1991. 
[17] Pasetto, Marco, and Nicola Baldo, "Fatigue behavior characterization of bituminous mixtures made with reclaimed asphalt pavement and steel slag," Procedia-Social and Behavioral Sciences, vol. 53, pp. 297-306, 2012.

[18] Erlin, Bernard, and Dipayan Jana, "Forces of hydration that can cause havoc in concrete," Concrete international, vol. 25 , no. 11 , pp. 51-57 2003.

[19] Muhmood, Luckman, Satish Vitta, and D. Venkateswaran, "Cementitious and pozzolanic behavior of electric arc furnace steel slags," Cement and Concrete Research, vol. 39, no. 2, pp. 102-109, 2009.

[25] Grade, A S. (November 14, 2011). Basic Oxygen Steel Making Information. [online] Available: http://www.gradeasteel.com/basic_oxygen_steelmaking/encyclopedia.htm

[21] Lun, Yunxia, et al, "Methods for improving volume stability of steel slag as fine aggregate." Journal of Wuhan University of Technology-Mater, Sci. Ed, vol. 23, no. 5, pp. 737-742, 2008.

[22] Manso, Juan M., et al, "Ladle furnace slag in construction," Journal of materials in civil engineering, vol. 17, no. 5, pp. 513-518, 2005.

[23] Rohde, Luciana, Washington Peres Núñez, and Jorge Augusto Pereira Ceratti, "Electric arc furnace steel slag: base material for low-volume roads," Transportation research record, vol. 1819, no. 1, pp. 201-207, 2003.

[24] Khalafalla, Mohamed, and Mbakisya Onyango, "Overview of the use of recycled materials in pavement," 2014.

[25] Chen, Zongwu, et al, "Utilization of gneiss coarse aggregate and steel slag fine aggregate in asphalt mixture," Construction and Building Materials, vol.93, pp. 911-918, 2015.

[26] Masoudi, Sajjad, Sayyed Mahdi Abtahi, and Ahmad Goli, "Evaluation of electric arc furnace steel slag coarse aggregate in warm mix asphalt subjected to long-term aging," Construction and Building Materials, vol. 135, pp. 260266, 2017.

[27] Manso, Juan M., et al, "Ladle furnace slag in construction," Journal of materials in civil engineering, vol. 17, no. 5, pp. 513-518, 2005.

[28] American Association of State Highway and Transportation Officials, "Bulk Specific Gravity of Bituminous Mixtures Using Saturated Surface Dry Specimens, Test Method AASHTO T 166-00," Standard Specifications for Transportation Materials and Methods of Sampling and Testing, Part II - Tests, Twentieth Edition, 2000.

[29] T. K. Pellinen, "Investigation of the Use of Dynamic Modulus as an Indicator of Hot-Mix Asphalt Performance," Ph.D. Dissertation, Arizona State University, Tempe, AZ, 2001.

[30] Witczak, Matthew W, "Simple performance test for superpave mix design," Transportation Research Board, vol. 465, 2002.

[31] American Association of State Highway and Transportation Officials, "Standard Method of Test For Determining Dynamic Modulus of Hot-Mix Asphalt Concrete Mixtures. Test Method AASHTO, T 342-11, Standard specifications for transportation materials and methods of sampling and testing, Washington D.C., 2011.

[32] K. P. Biligiri, "Improved Method to Determine Tertiary Flow for Asphalt Mixtures," Master of Science Thesis, Arizona State University, Tempe AZ, 2005. 